\title{
Numerical Model Validation for Mengkulang Glulam Timber Bolt Withdrawal Capacity
}

\author{
Mohd Nizam Shakimon ${ }^{1}$, Rohana Hassan ${ }^{2, *}$, Mohamed Ali Hassan ${ }^{1}$, Nor Jihan Abd Malek ${ }^{3}$, Norshariza \\ Mohamad Bhkari ${ }^{2}$ Mohd Sapuan Salit ${ }^{4}$ \\ ${ }^{1}$ Faculty of Engineering \&Technology Infrastructure, Infrastructure University Kuala Lumpur (IUKL), Malaysia \\ ${ }^{2}$ Institute for Infrastructure Engineering and Sustainable Management (IIESM), Universiti Teknologi MARA, Malaysia \\ ${ }^{3}$ SEGi University and Colleges (SEGi), Malaysia \\ ${ }^{4}$ Laboratory of Biocomposite Technology, Institute of Tropical Forestry and Forest Products (INTROP), Universiti Putra Malaysia (UPM), \\ Malaysia
}

Received November 29, 2021; Revised February 14, 2022; Accepted February 23, 2022

\section{Cite This Paper in the following Citation Styles}

(a): [1] Mohd Nizam Shakimon, Rohana Hassan, Mohamed Ali Hassan, Nor Jihan Abd Malek, Norshariza Mohamad Bhkari, Mohd Sapuan Salit, "Numerical Model Validation for Mengkulang Glulam Timber Bolt Withdrawal Capacity," Civil Engineering and Architecture, Vol. 10, No. 2, pp. 715-724, 2022. DOI: 10.13189/cea.2022.100226.

(b): Mohd Nizam Shakimon, Rohana Hassan, Mohamed Ali Hassan, Nor Jihan Abd Malek, Norshariza Mohamad Bhkari, Mohd Sapuan Salit (2022). Numerical Model Validation for Mengkulang Glulam Timber Bolt Withdrawal Capacity. Civil Engineering and Architecture, 10(2), 715-724. DOI: 10.13189/cea.2022.100226.

Copyright $\bigcirc 2022$ by authors, all rights reserved. Authors agree that this article remains permanently open access under the terms of the Creative Commons Attribution License 4.0 International License

\begin{abstract}
The adequacy of timber joints determines how much load it can sustain, commonly called load-carrying capacity. European Yield Model (EYM), also known as Johansen yield theory, has been widely adopted in the design of timber joints for predicting load-carrying capacity. In EC5, the pulling out capacity is known as the 'rope effect' and becomes one parameter that governs the load-carrying capacity in a dowel-type timber connection. Due to the high cost of preparing the timber specimen, computer modelling always becomes the alternative in measuring the load-carrying capacity for timber connections. However, the computer modelling results need to be validated with the experimental laboratory test before being extended to different sizes and materials of fasteners. This study presents a finite element method (FEM) for numerical modelling and analysis to validate the experimental performance of timber's $12 \mathrm{~mm}$, $16 \mathrm{~mm}$, and $20 \mathrm{~mm}$ bolt withdrawal capacity. This method adopted Abaqus 6.14.4 software package to create four (4) FEM models consisting of a bolt inserted into a glulam timber block at a different insertion depth, parallel and perpendicular to the timber grain direction. The axially inserted bolt was subjected to a pull-out force while the glulam timber block was held in position. The mild steel bolt and tropical Mengkulang glulam timber blocks were
\end{abstract}

used. The validation showed an acceptable agreement between the FEM and the experimental results.

Keywords European Yield Model, Glulam, Structural Material, Withdrawal Capacity

\section{Introduction}

Due to its natural resources, Malaysia has traditionally been known for its wood-based furniture. Malaysian woods are widely prized for usage in furniture such as sofas, dining tables, and cabinets due to their features. Subsequently, Malaysia is among the top ten largest furniture exporters in the world, with the country exporting over $80 \%$ of its furniture manufacturing [1]. As a result, less development was paid for, for structural and engineered timber development. Despite the fact that engineered wood products (EWP) have been evolving from solid wood for decades around the world [2], glued laminated (glulam) timber and cross-laminated timber (CLT) are relatively new in Malaysia [3]. EWPs are not exclusively used as structural members locally since not much engineering information about designing using EWPs made of tropical timber is available. Some studies 
were found laminating tropical bamboo species as laminated timber (LBT) and being observed as wood replacement [4].

Currently, ninety-four (94) total species are classified in the MS544: Part 2: 2001 [5]. One of the most common tested species reported for glulam is Mengkulang. The scientific name for Mengkulang timber is Heritiera spp. Mengkulang timber is from a Medium Hardwood species with a $625-895 \mathrm{~kg} / \mathrm{m} 3$ air dry density. This timber is not durable if used in contact with the ground as it is very susceptible to damage by termites and is liable to fungal infestation. On the other hand, it is entirely satisfactory for use in reasonably dry, well-ventilated positions free from termite attacks. Test sticks treated by the full-cell process with an average absorption of $119 \mathrm{~kg} / \mathrm{m} 3(7.4 \mathrm{lb} / \mathrm{ft} 3)$ were found to be serviceable after 13 years [6]. It is not difficult to treat with preservatives and is classified as "average." The texture is slight to moderately coarse but with straight to shallowly interlocked grain. Mengkulang timber falls into strength group (SG) 5 [5], and the glulam manufacturing are specified in Malaysian Standard MS 758: 2001 [7]. While the code of practice for structural use of timber for Permissible Stress Design of Glued Laminated Timber can be referred to the Malaysian Standard MS 544: Part 3: 2001 [8] and Malaysian Standard MS 544: Part 5: 2017 [9] for timber joints. However, these two (2) relevant standards are relatively limited in detailing the EWPs' connection.

Johansen [10] created the first theoretical model and, up to now, remain as the basis of reference for accurately estimating the lateral load-carrying capacity of timber mechanical connections based on the yielding capacity of the fastener and the embedment capacity of the timber portion underneath the fastener. Johansen's model was later refined and incorporated into the European design specification's European Yield Model (EYM) equations. Since then, EYM has been extensively used in wood design codes for dowel-type connections, including the United States National Design and Specification (NDS) [11] and the Eurocode (EC5) [12] for timber.

According to EYM specified in EC5 [12], the modes of failure and the load-carrying capacity of timber connection is governed by the bending of the fastener, timber embedment capacity and fastener withdrawal capacity. A similar observation has been made in tests by Stamatopoulos and Malo [13] on the strength and stiffness of screwed-in threaded rods embedded in softwood. Test results were used to derive expressions for the axial capacity and stiffness.

\subsection{Withdrawal Capacity}

The dowel withdrawal capacity is influenced by the engineering properties of the dowel diameter, the contact surface between the dowel and timber, the withdrawal speed rate, grain directions, condition of the pre-drilled hole of the timber, insertion depth and timber density [14]. The withdrawal capacity for the Mengkulang glulam on the effects of grain direction was reported by Hassan et al. [15] and Abd Malek et al. [16]. While the experimental effects on withdrawal resistance for dowel embedment depth were studied on Merbau species by Ab Rahman et al. [17]. As prescribed by EC5 [12], the experimental test shall be used to determine the withdrawal capacity of the dowel. However, it is time-consuming and costly. On the other hand, insufficient edge and end distances or spacings may affect the effectiveness of connections with many axially loaded fasteners, as failure modes other than withdrawal or steel failure may be triggered, and the entire axial capacity may not be reached. Therefore, the minimum edge and end distances and fastening spacings are regulated and must be accomplished during the joint assembling [13].

\subsection{Finite Element Modeling (FEM)}

Due to the high cost of preparing the timber samples, the finite element method (FEM) is the alternative to validate the experimental works. The FEM generates extensive results for various structural element dimensions or materials by varying the study's input parameters. Depending on available data, its simulations' accuracy depends on the model's complexity, such as the directional dependency of material properties, constitutive models, and failure criteria. Most FEM considers the different mechanical behaviours in the various loading directions by adopting the ductile elastic-plastic behaviour in compression and brittle elastic in tension and shear. Some authors assume a linear-elastic perfectly-plastic behaviour in compression [18-23].

Furthermore, the success of the FEM is largely dependent on the convergence of the finite element analysis. Convergence is affected by various factors, including the model's complexity, mesh size, mesh type and shape, material properties, and analysis technique $[25,26]$. Different mesh sizes can produce significantly different convergence results and stress-strain curves $[26,27]$. The fewer meshing nodes require less computation time but are less accurate [27]. The more nodes in a mesh shape smaller than $0.1 \mathrm{~mm}$ may result in improved and consistent accuracy, but convergence error may occur, especially in quadrilateral shape element meshes [27,28] and simplified models [27].

Shell and solid elements are frequently used in FEM to achieve convergence, with the latter performing better in 3D beam analysis but being more time consuming [29]. While brittle material is appropriate for unstructured meshes in a 3D model [25] plastic elements are preferred for convergence studies to avoid FEA failures. The Hill yield criterion demonstrates superior convergence to the Hoffman yield criterion when simulating the elasto-plastic behaviour of wood $[23,24]$. This criterion is a generalised version of the Von-Mises yield criterion that considers the anisotropic nature of the wood [24].

The FEM is the dominant discretisation technique in structural mechanics. The basic concept in the physical interpretation of the FEM is the subdivision of the 
mathematical model into disjoint (non-overlapping) components of simple geometry called finite elements or elements for short. An element response is expressed as a finite number degree of freedom, characterised as the value of unknown functions at a nodal point. The response of the mathematical model is approximated by that of the discrete model obtained by assembling the collection of all elements [30].

The disconnection-assembly concept is practical when examining many artificial and natural systems. For example, it is easy to visualise an engine, bridge, building, aeroplane, or skeleton fabricated from simpler components. Unlike finite difference models, finite elements do not overlap in space. FEM is very useful in understanding the thermo-mechanical behaviour of any physical process. Hence, it is used widely in industrial applications as it can save time and the overall cost of the product. Today, almost every industry and educational institution worldwide use FEM to simulate a process, analyse the observations, and validate it using the experimental results [30].

Therefore, the objective of this study is to determine the withdrawal capacity of bolt diameter $12 \mathrm{~mm}, 16 \mathrm{~mm}$ and $20 \mathrm{~mm}$ on Mengkulang glulam, loaded parallel and perpendicular to the grain directions experimentally and validate using the FEM.

\section{Materials and Methods}

\subsection{Experimental Set-up}

The specimen's preparations and experimental work of
Mengkulang glulam were accomplished at the School of Civil Engineering, Universiti Teknologi MARA structural laboratory. The $12 \mathrm{~mm}, 16 \mathrm{~mm}$ and $20 \mathrm{~mm}$ diameter half-threaded $45 \mathrm{~mm}$ galvanised steel bolts were inserted parallel and perpendicular to the grain direction in the Mengkulang glulam timber blocks samples.

The samples were tested using Universal Testing Machine (UTM) under a uniform speed rate of $2.54 \mathrm{~mm} / \mathrm{min}$ pulling force. A total of fourteen (14) glulam timber block samples with dimensions of $130 \mathrm{~mm} \times 150$ $\mathrm{mm} \times 65 \mathrm{~mm}(\mathrm{~b} \times \mathrm{h} \times \mathrm{t})$ were prepared for withdrawal load parallel and perpendicular to the glue line (Figure 1).

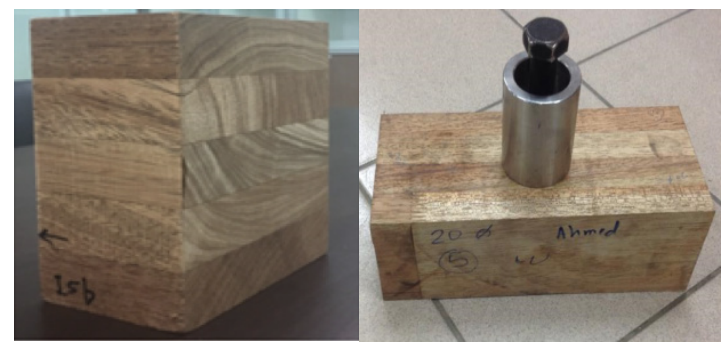

A

B

Figure 1. Glulam timber block sample (a) perpendicular to the grain (b) parallel to the grain

All bolts were made of mild steel. The sample's dimension was determined according to the minimum spacing, end distance, and edge distance of the bolt specified in EC5 [12] (Table 1). Other specifications on the test method were based on ASTM D1761-14[14].

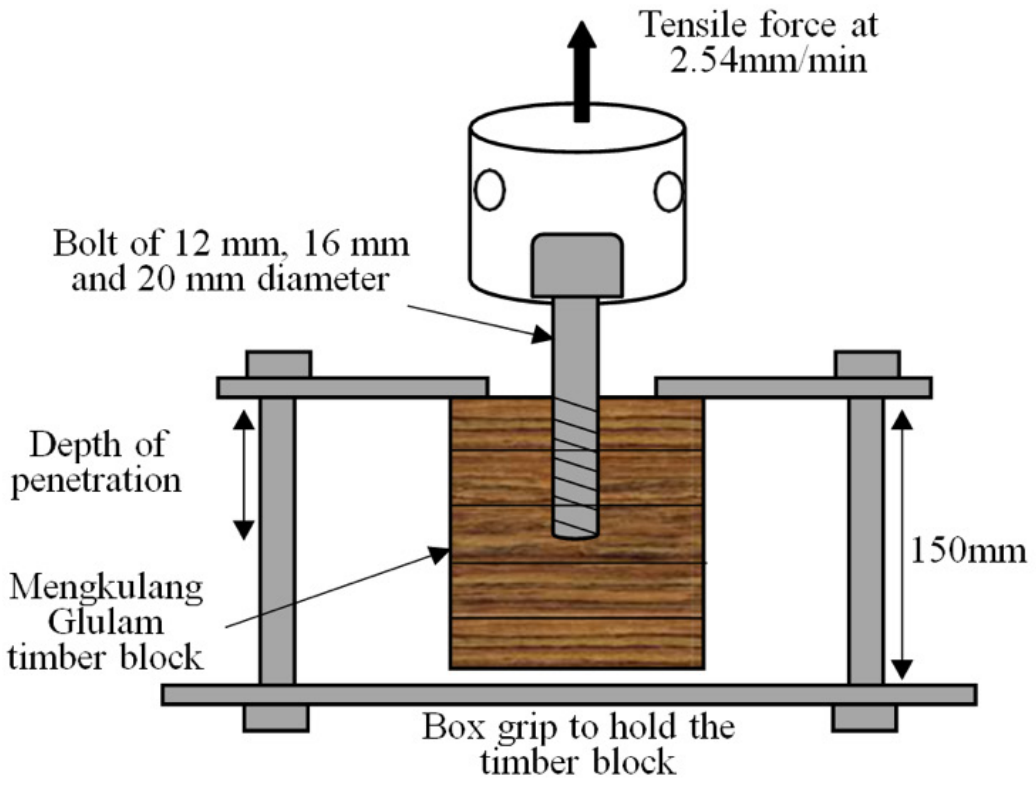

A

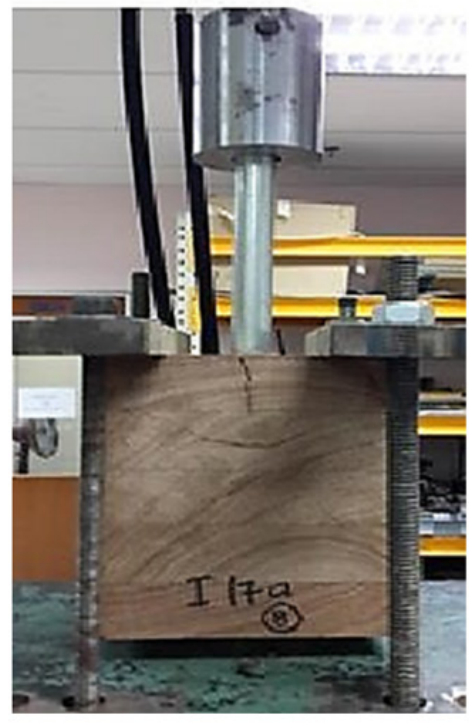

B

Figure 2. Glulam timber block in the test set up (A) Schematic test set up (B) Experimental test set up 
The glulam timber block samples were marked at the centre points to allow an accurate bolt insertion position. The timber samples' holes were prepared with diameters equal to the bolt diameter or $2 \mathrm{~mm}$ less to prevent bolts friction loss in the specimens. The bolts were inserted 39 $\mathrm{mm}, 40 \mathrm{~mm}$, and $41 \mathrm{~mm}$ into the timber block specimens for bolt sizes $12 \mathrm{~mm}, 16 \mathrm{~mm}$, and $20 \mathrm{~mm}$, respectively. Figure 2 shows the glulam timber block test set up accordingly.

Table 1. Minimum values of spacing of edge and end distance for steel bolts (EC 5:2008)

\begin{tabular}{|c|c|c|}
\hline $\begin{array}{c}\text { Spacing and end/edge } \\
\text { distances }\end{array}$ & Angle & $\begin{array}{c}\text { Minimum spacing or } \\
\text { distance }\end{array}$ \\
\hline$a_{1}$ (parallel to grain) & $0^{\circ} \leq \alpha \leq 360^{\circ}$ & $(4+|\cos \alpha|) d$ \\
\hline $\mathrm{a}_{2}$ (perpendicular to grain) & $0^{\circ} \leq \alpha \leq 360^{\circ}$ & $4 d$ \\
\hline$a_{3,1}$ (loaded end) & $\begin{array}{c}-90^{\circ} \leq \alpha \leq \\
90^{\circ}\end{array}$ & $\max (7 \mathrm{~d} ; 80 \mathrm{~mm})$ \\
\hline \multirow[t]{3}{*}{$a_{3, c}($ unloaded end $)$} & $\begin{array}{c}90^{\circ} \leq \alpha \leq \\
150^{\circ}\end{array}$ & $\max [(1+6 \sin \alpha) \mathrm{d} ; 4 \mathrm{~d}]$ \\
\hline & $\begin{array}{c}150^{\circ} \leq \alpha \leq \\
210^{\circ}\end{array}$ & $4 d$ \\
\hline & $\begin{array}{c}210^{\circ} \leq \alpha \leq \\
270^{\circ}\end{array}$ & $\max [(1+6 \sin \alpha) \mathrm{d} ; 4 \mathrm{~d}]$ \\
\hline $\mathrm{a}_{4,1}$ (loaded edge) & $0^{\circ} \leq \alpha \leq 180^{\circ}$ & $\max [(2+2 \sin \alpha) \mathrm{d} ; 3 \mathrm{~d}]$ \\
\hline $\mathrm{a}_{4, \mathrm{c}}$ (unloaded edge) & $\begin{array}{c}180^{\circ} \leq \alpha \leq \\
360^{\circ}\end{array}$ & $3 d$ \\
\hline
\end{tabular}

The bolt withdrawal strength was determined from the maximum load required to pull out the bolt from the glulam timber block. It is a maximum withdrawal load over its penetration depth, as expressed in (1).

$$
\mathrm{W}=\mathrm{P}_{\max } / \mathrm{L}
$$

where;

$$
\begin{aligned}
& W \quad=\text { withdrawal strength, } \mathrm{N} / \mathrm{mm} \\
& \mathrm{P}_{\max } \quad=\text { maximum tensile withdrawal load, } \mathrm{N} \\
& \mathrm{L}=\text { bolt insertion depth, } \mathrm{mm}
\end{aligned}
$$

\subsection{Modelling Framework}

\subsubsection{Computational Set-up}

The FEM of the Mengkulang glulam timber block samples were generated using the Abaqus interface, based on the specified insertion depth, the layout of bolts, sample geometry, material properties, materials interaction, material orientations and the loading. The analyses were then submitted to the Abaqus solver to generate the database output and analyses the maximum tensile load.

\subsubsection{Generate FEM Model}

The FEM models were generated comprising a model database (.cae file) and an input file that contained the geometry of the various model parts of steel bolt and the Mengkulang glulam timber block sample with their assembly, the material and mechanical properties, the contact interaction between the bolt and the timber block sample, the boundary conditions, the type of analysis steps and the corresponding output requests, the mesh details; to be submitted to the Abaqus solver, representing the analysis to be performed (.inp file). The geometry of the various model are parts of steel plate, bolts, and timber with their position in the model assembly.

The Mengkulang glulam timber block sample was defined as orthotropic material to follow the Cartesian coordinates with three mutually perpendicular axes of elastic symmetry at each point [31] (Figure 3).

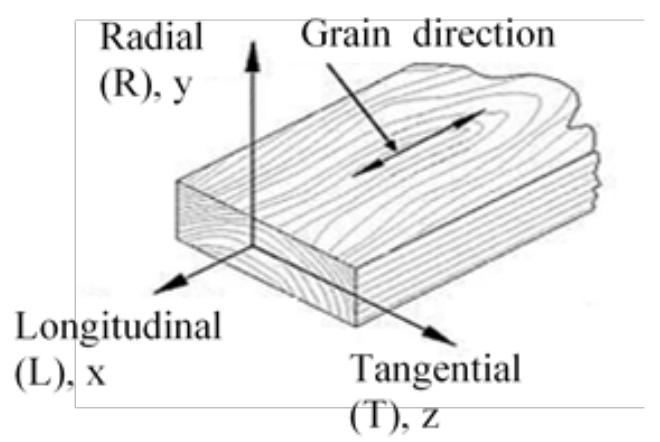

Figure 3. Orthotropic axes system

In total, nine (9) independent elastic constants were defined. The value of $E_{1}$ of $10800 \mathrm{~N} / \mathrm{mm}^{2}$ was based on MS544 Part 3: 2001[8] for the mean modulus of elasticity for Mengkulang glulam timber (D40). Table 2 shows the values of independent elastic constants: $E_{2}, E_{3}, v_{21}, v_{31}$, $v_{32}, G_{12}, G_{23}, G_{31}$. These values were determined based on the ratios reported by Ahmad [18] and Green \& Winandy [32]. The timber grain directions, either parallel or perpendicular to the direction of loading, were modelled by establishing material orientations with an additional rotation angle of 90 and 0 for parallel and perpendicular, respectively. The steel bolt was defined as isotropic material. The standard value of $210000 \mathrm{~N} / \mathrm{mm}^{2}$ for Young's modulus and 0.3 for Poisson's ratio were used for the steel material.

Table 2. Values of independent elastic constants

\begin{tabular}{|c|c|c|c|c|c|c|c|c|}
\hline $\mathrm{E}_{1}\left(\mathrm{~N} / \mathrm{mm}^{2}\right)$ & $\begin{array}{c}\mathrm{E}_{2} \\
\left(\mathrm{~N} / \mathrm{mm}^{2}\right)\end{array}$ & $\begin{array}{c}\mathrm{E}_{3} \\
\left(\mathrm{~N} / \mathrm{mm}^{2}\right)\end{array}$ & $v_{21}$ & $v_{31}$ & $v_{32}$ & $\begin{array}{c}\mathrm{G}_{12} \\
\left(\mathrm{~N} / \mathrm{mm}^{2}\right)\end{array}$ & $\begin{array}{c}\mathrm{G}_{23} \\
\left(\mathrm{~N} / \mathrm{mm}^{2}\right)\end{array}$ & $\begin{array}{c}\mathrm{G}_{31} \\
\left(\mathrm{~N} / \mathrm{mm}^{2}\right)\end{array}$ \\
\hline 10800 & 864 & 939.13 & 0.015 & 0.35 & 0.015 & 1177.2 & 302.4 & 831.6 \\
\hline
\end{tabular}


The general contact interaction was used for the steel bolt to timber contact surface instead of surface-to-surface contact interaction to simplify FEM modelling. The friction coefficient of 0.3 was used to simulate the friction developed in the bolt and timber contact surface.

The boundary conditions were defined on the top surface of the Mengkulang glulam timber block as having held in the vertical position. The tensile load with automatic incrementation allows the FEM model to be tested until failure. The small increment size of $0.1,0.015$, and 0.3 for the initial, minimum and maximum increment sizes was used to avoid error when submitting the FEM model to the Abaqus solver for analysis.

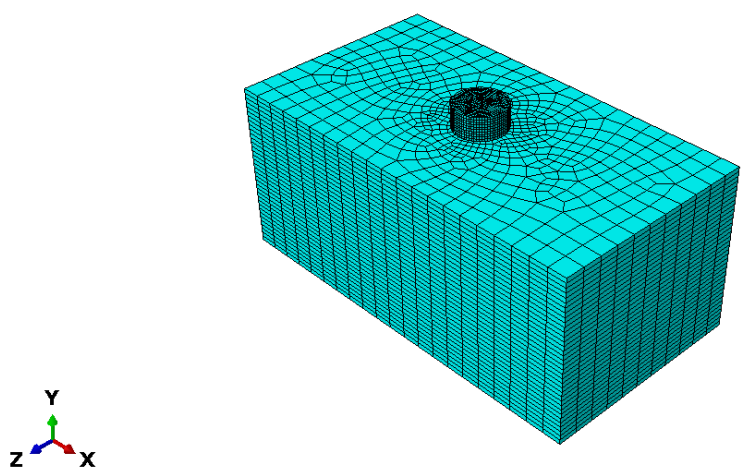

Figure 4. Typical FEM model of the Mengkulang timber block

\subsubsection{Run Simulations}

The FEM models were submitted to the Abaqus solver for analysis, and the process took less than two hours to complete due to less complex FEM models with mesh sizes of 8 and 1 were used for the Mengkulang glulam timber block sample and the steel bolt. Several factors were identified that caused the longer completion time, such as the finer mesh size, the mesh shape and type.

\subsubsection{Post-process Result}

The output database (.odb file) was created after the analysis was completed. The deformed model and the load-displacement curve can be generated and compared with the experimental data for validation.

\section{Results and Discussion}

\subsection{Withdrawal capacity of axially bolted Mengkulang Glulam for parallel and perpendicular directions}

Fourteen (14) specimens of each diameter of the steel bolts were tested in a perpendicular direction. Table 3 summarises the bolt withdrawal capacity for $12 \mathrm{~mm}, 16 \mathrm{~mm}$, and $20 \mathrm{~mm}$ in diameter. The experimental shows that the $20 \mathrm{~mm}$ bolt has the highest bolt withdrawal capacity, with the $16 \mathrm{~mm}$ bolt lesser by $33.31 \%$, and the $12 \mathrm{~mm}$ bolt is lesser by $66.36 \%$.

Table 3. Summary of experimental average bolt withdrawal strength

\begin{tabular}{|c|c|c|c|c|c|}
\hline \multirow{2}{*}{$\begin{array}{c}\text { Bolt } \\
\text { Dia. } \\
\text { d } \\
(\mathrm{mm})\end{array}$} & $\begin{array}{c}\text { Insertion } \\
\text { Depth } \\
\mathrm{L} \\
(\mathrm{mm})\end{array}$ & $\begin{array}{c}\text { Max. } \\
\text { With- } \\
\text { drawal } \\
\text { Load, } \\
\mathrm{P}_{\max } \\
(\mathrm{N})\end{array}$ & $\begin{array}{c}\text { With- } \\
\text { drawal } \\
\text { Capacity } \\
\text { W } \\
(\mathrm{N} / \mathrm{mm})\end{array}$ & $\begin{array}{c}\text { Max. } \\
\text { With- } \\
\text { drawal } \\
\text { Load, } \\
(\mathrm{N})\end{array}$ & $\begin{array}{c}\text { With- } \\
\text { drawal } \\
\text { Capacity, } \\
\mathrm{W} \\
(\mathrm{N} / \mathrm{mm})\end{array}$ \\
\hline 12 & 39 & 16480 & 422.56 & 6780 & 173.85 \\
\hline 16 & 40 & 26680 & 667 & 11990 & 299.75 \\
\hline 20 & 41 & 19122 & 466.39 & - & - \\
\hline
\end{tabular}

The typical load-displacement curves of bolt withdrawal capacity for $12 \mathrm{~mm}, 16 \mathrm{~mm}$, and $20 \mathrm{~mm}$ for perpendicular and parallel grain directions are shown in Figure 5 and Figure 6 . The curves depict that the bolt diameter affects the withdrawal load. The withdrawal capacity shows positive relation to the brittle failure projected by the bolt diameter.

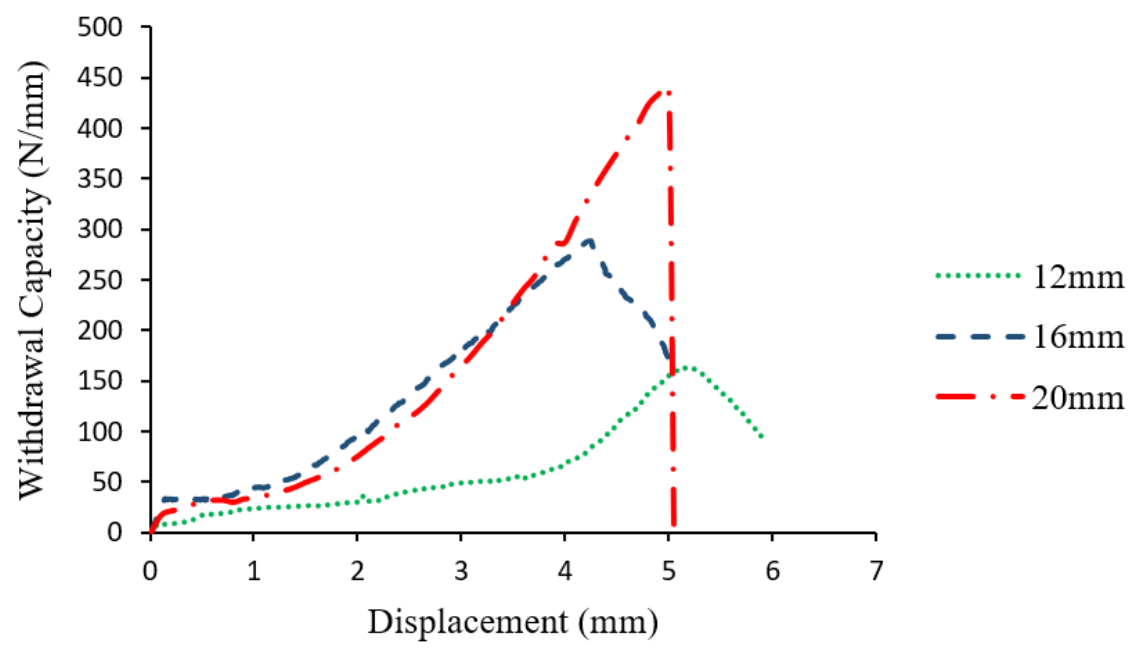

Figure 5. Typical curve of bolt withdrawal capacity vs displacement for $12 \mathrm{~mm}, 16 \mathrm{~mm}$, and $20 \mathrm{~mm}$ perpendicular to the grain 


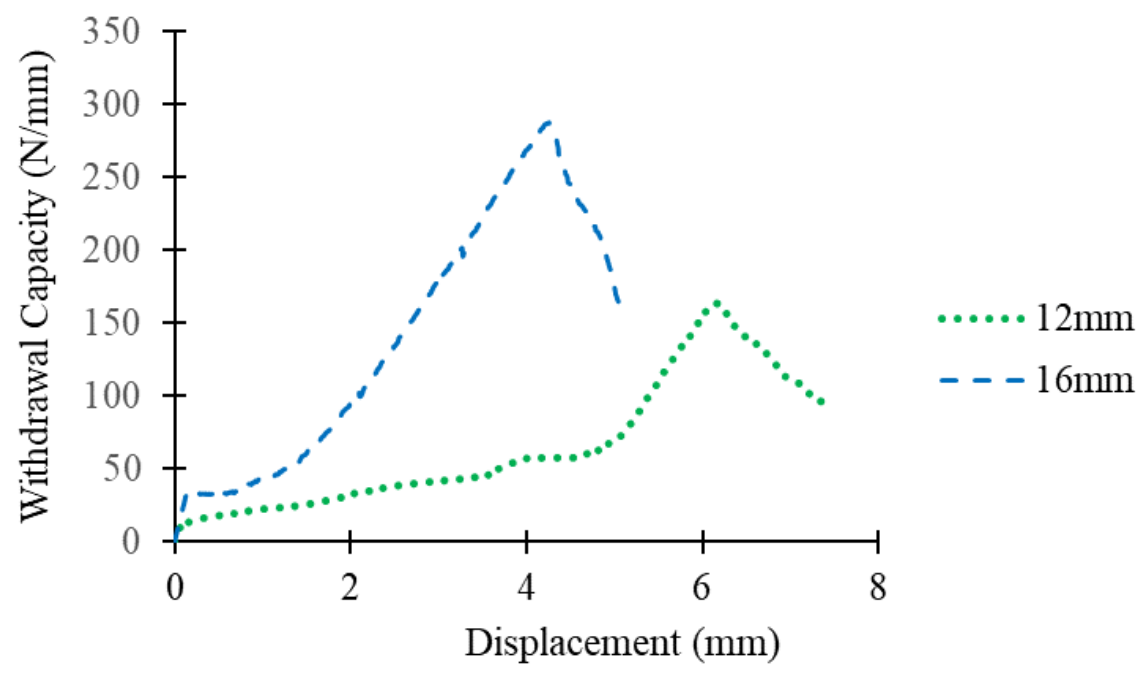

Figure 6. Typical curve of bolt withdrawal capacity vs displacement for $12 \mathrm{~mm}$ and $16 \mathrm{~mm}$ parallel to the grain.

\subsection{Failure Modes}

The inserted bolts in the glulam timber block samples were tested until failure. This failure can be related to the bolt's surface contact area and the timber to provide bolt withdrawal resistance. It was observed that the $20 \mathrm{~mm}$ bolt has the highest resistance to bolt withdrawal. However, it failed much earlier and was even more brittle than the other two bolts. Although the $12 \mathrm{~mm}$ and $16 \mathrm{~mm}$ bolts have lower withdrawal capacity than the $20 \mathrm{~mm}$ bolt, the failures were slightly ductile.

Nevertheless, a bigger diameter cannot be used for the loaded parallel to the grain direction as it caused the Mengkulang glulam timber to fail abruptly. The failure for parallel grain direction was found more brittle than the perpendicular due to the splitting failure in the samples (Figure 7). The responses of splitting failures are implicitly specified in EN 1995-1-1[12] by the minimum end/edge distances and spacing and minimum angle to the grain, less than $30^{\circ}$.

It shows that the failure was vulnerable to cracks along the grain. The single crack along the grain has led to a considerable loss of strength. Hence, disintegration of contact between the bolt and the surrounding glulam timber.

The findings agreed with a previous study [13], where the axially-loaded screws installed in a solid timber at an angle to grain smaller than $30^{\circ}$ is not allowed. The reasons brought this study to only cover a small number of tests and only tested for the two diameters of bolts for the parallel. Thus, this study supports the clarification as to the threaded bolts exactly parallel to the grain $\left(\alpha=0^{\circ}\right)$ direction should be avoided.

\subsection{FEM Validation}

Based on the FEM validation, there is no doubt that both experiment and modelling results are almost similar. The load versus displacement capacity is the indicator for the validity of the results of an explicit analysis. Based on comparisons shown in Table 4 between FEM and experimental results of the two selected diameters loaded perpendicular and parallel to the grain, the analysis has yielded a similar pattern and behaviour and a close value of load-carrying capacity.

The study demonstrates the positive agreement between the FEM and experimental, considering supported findings in previous studies [27], [24]. Therefore it can be concluded that the results performed in the FEM models are acceptable. Figures $8-11$ show the typical results of different case studies for this presentation.
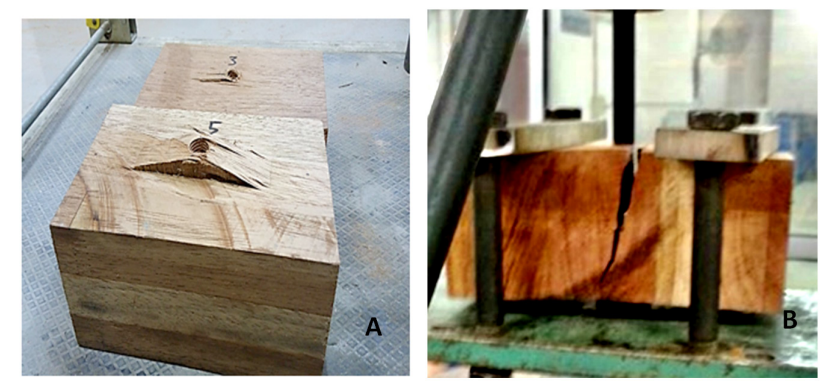

Figure 7. Typical failure mode under bolt withdrawal test: (A) perpendicular to the grain direction (B) parallel to the grain direction. 
Table 4. Comparison FEM vs experimental (Exp) of bolt withdrawal load

\begin{tabular}{|c|c|c|c|c|c|c|c|}
\hline \multirow{3}{*}{$\begin{array}{c}\text { Bolt Dia. } \\
\quad \text { d } \\
(\mathrm{mm})\end{array}$} & \multirow{3}{*}{$\begin{array}{c}\text { Insertion Depth } \\
\text { L } \\
(\mathrm{mm})\end{array}$} & \multicolumn{3}{|c|}{ Perpendicular } & \multicolumn{3}{|c|}{ Parallel } \\
\hline & & \multicolumn{3}{|c|}{ Max. Withdrawal Load, $\mathrm{P}_{\max }(\mathrm{N})$} & \multicolumn{3}{|c|}{ Max. Withdrawal Load, $\mathrm{P}_{\max }(\mathrm{N})$} \\
\hline & & FEM & Exp & $\Delta \%$ & FEM & Exp & $\Delta \%$ \\
\hline 12 & 39 & 17720 & 16480 & 1.09 & 7330 & 6780 & 7.50 \\
\hline 16 & 40 & 26980 & 26680 & 1.11 & 13900 & 11990 & 13.74 \\
\hline
\end{tabular}

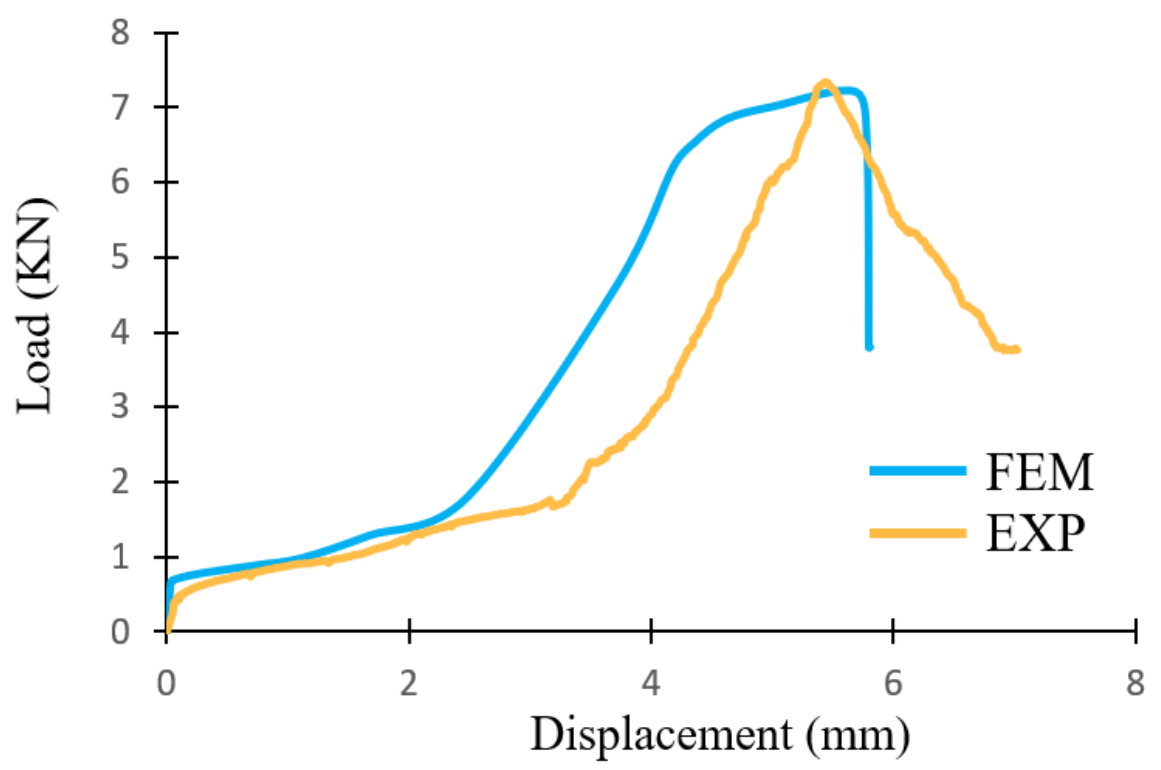

Figure 8. Load vs displacement curves for $12 \mathrm{~mm}$ bolt diameter withdrawal capacity inserted parallel to the grain (FEM vs experiment)

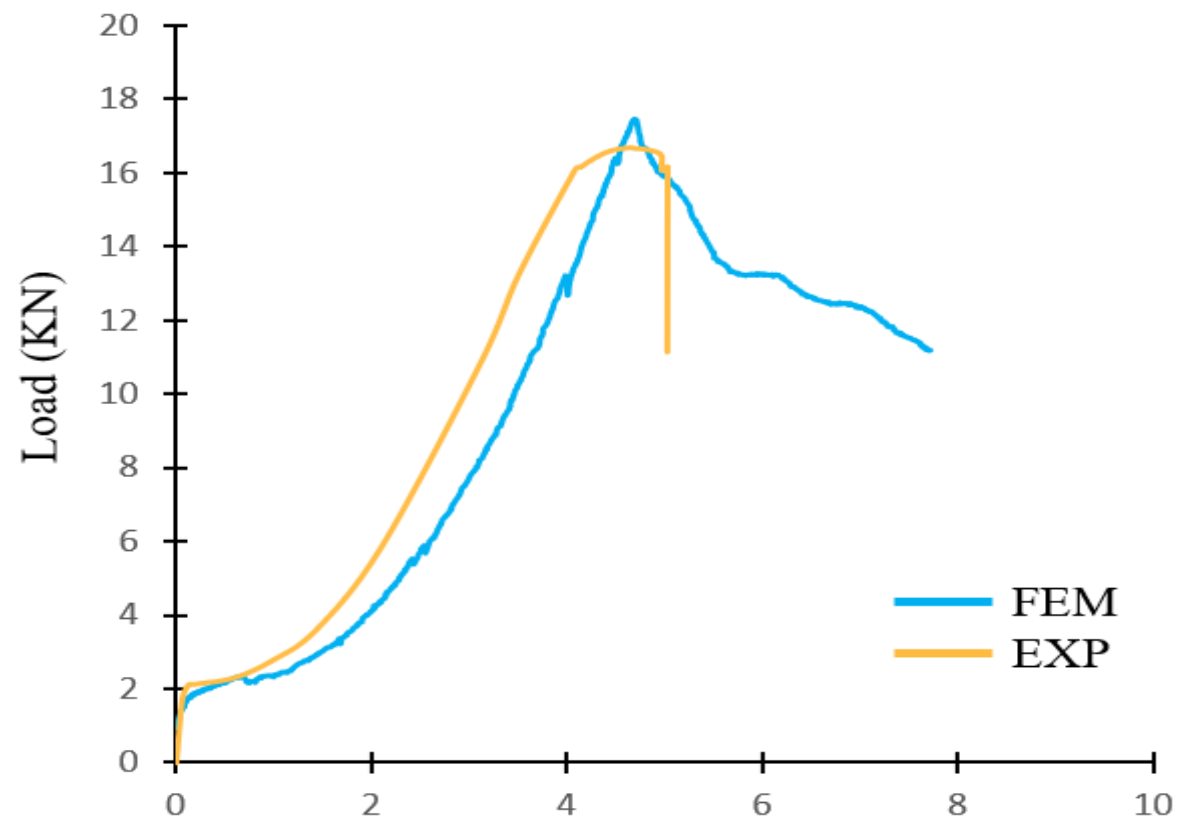

Displacement ( $\mathrm{mm})$

Figure 9. Load vs displacement curves for $12 \mathrm{~mm}$ bolt diameter withdrawal capacity inserted perpendicular to the grain (FEM vs Experiment). 


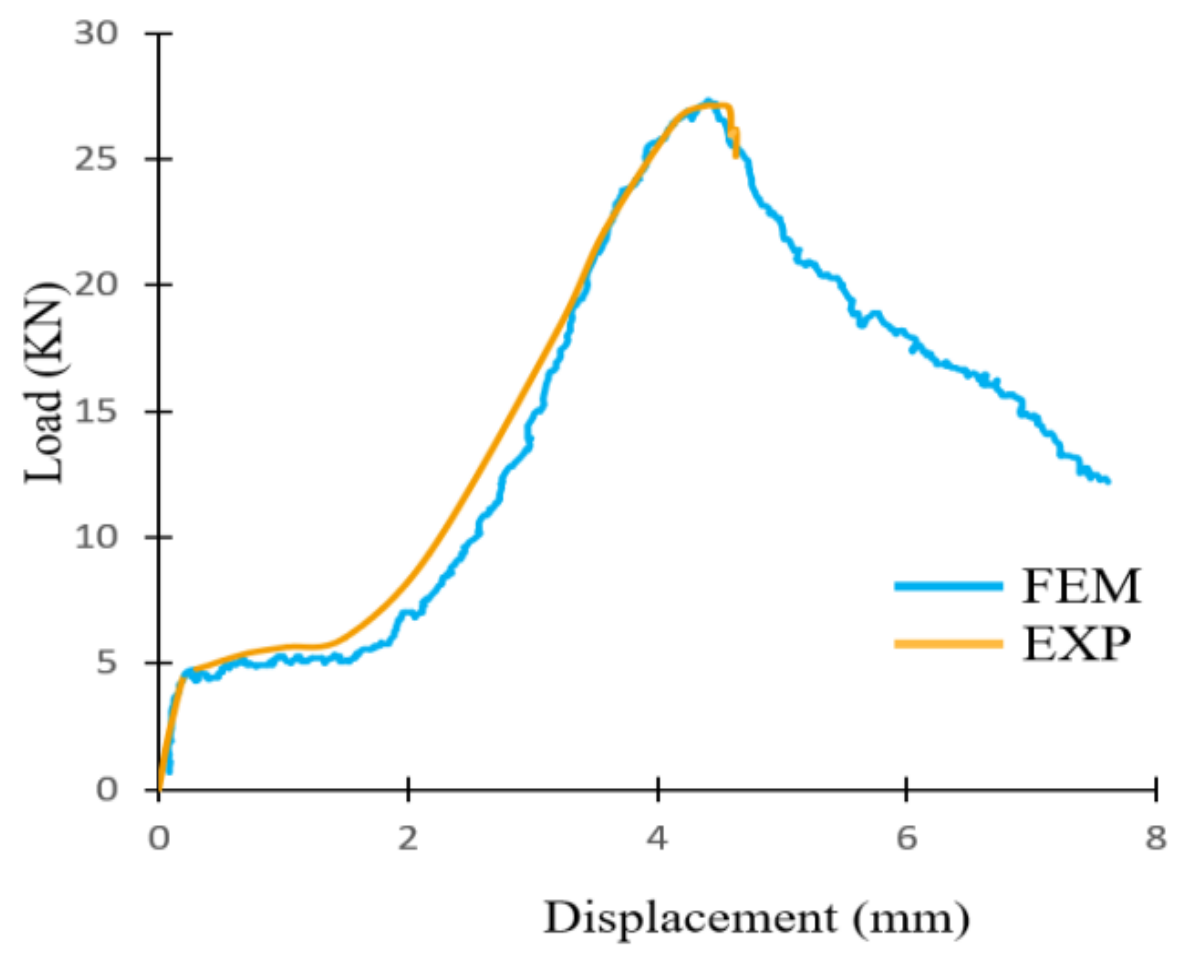

Figure 10. Load vs displacement curves for $16 \mathrm{~mm}$ bolt diameter withdrawal capacity inserted parallel to timber grain (FEM vs Experiment).

The bolt withdrawal capacity for $12 \mathrm{~mm}, 16 \mathrm{~mm}$, and $20 \mathrm{~mm}$ bolts parallel and perpendicular to the timber grain was successfully determined. The Mengkulang timber samples with dowels inserted perpendicularly show greater values than the parallel, even for the smallest $12 \mathrm{~mm}$ diameter. The $20 \mathrm{~mm}$ bolt delivers optimum performance in the withdrawal force required to pull the bolt out of the timber block sample in these three different bolt diameters. It can be related to the total contact surface area between the bolt and the timber. The larger the bolt diameter, the larger the contact surface area, hence the higher the friction between the bolt and the timber. However, a larger bolt diameter provides higher stiffness and rigidity, leading to bolt withdrawal's failure in timber brittle. This finding agrees with Stamatopoulos and Malo [13].

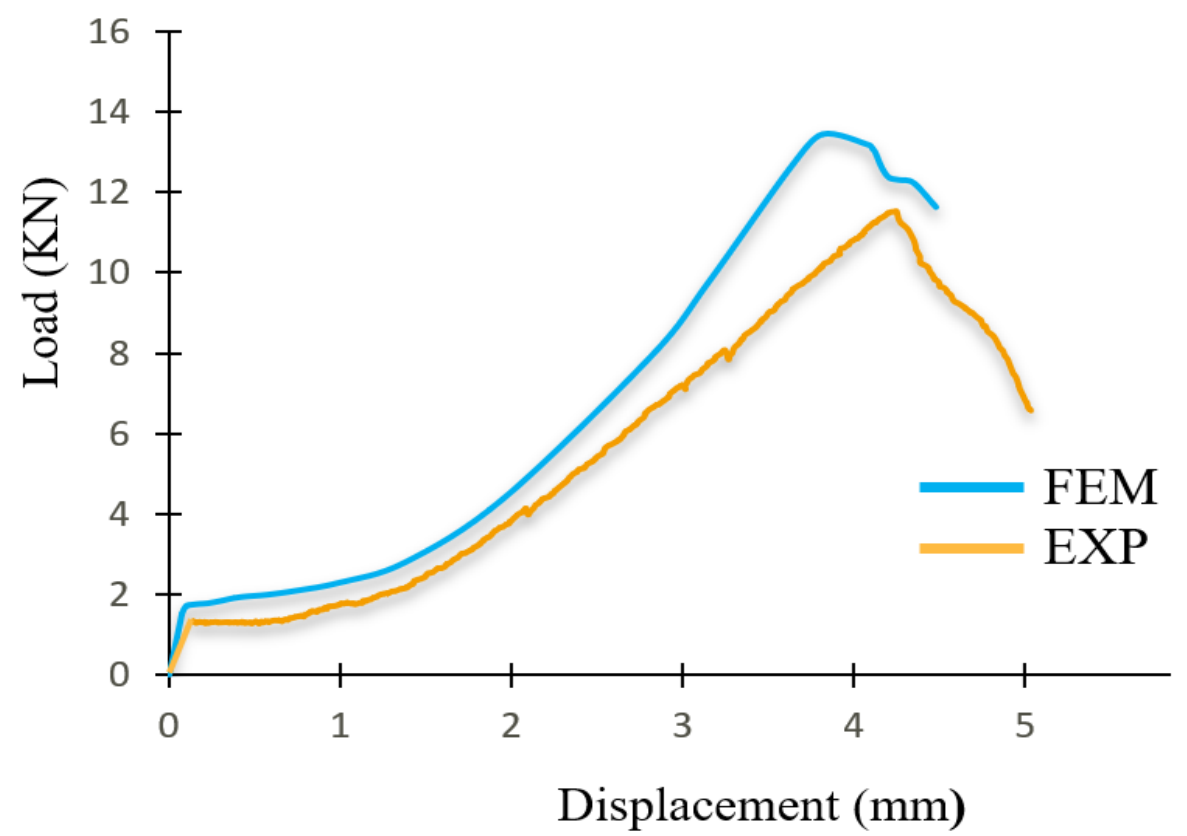

Figure 11. Load vs displacement curves for $16 \mathrm{~mm}$ bolt diameter withdrawal capacity inserted perpendicular to the grain (FEM vs Experiment). 


\section{Conclusions}

The withdrawal capacity observed from the FEM models showed variance in the manipulated factors: bolt diameters and the grain direction of timber block samples correspond to the bolt's insertion.

- The most significant contribution to the higher withdrawal capacity is the size of the bolt diameter instead of the grain direction.

- Comparing the maximum load between the FEM models and the experimental results showed $\pm 10 \%$ accuracy. Therefore, the FEM models are acceptable.

- The failure mode behaviour for parallel is more vulnerable than a perpendicular; thus, the design with threaded bolts exactly parallel to the grain $\left(\alpha=0^{\circ}\right)$ direction should be avoided.

\section{Acknowledgments}

The authors gratefully acknowledge the help of Universiti Teknologi MARA, Malaysia, for providing research grant 600-IRMI/MyRA 5/3/BESTARI (025/2017).

\section{REFERENCES}

[1] S. Ali, S. A. Hussain, M.Z. Mohd Tohir, and A. A, Nuruddin. Statistical Analysis of Malaysian Timber's Combustion Data from Cone Calorimeter Test. Pertanika Journal. Science. \& Technology. 28 (S1): 185-198, 2020. Journal homepage: http://www.pertanika.upm.edu.my/

[2] C. Lehringer and J. Gabriel. Review of Recent Research Activities on One-Component PUR-Adhesives for Engineered Wood Products. RILEM Bookseries, 9, 405-420, 2014. https://doi.org/10.1007/978-94-007-7811-5

[3] C. B. Ong. Glue-laminated timber (Glulam). In Wood Composites (pp. 123-140). (2015) Elsevier Ltd. https://doi.org/10.1016/b978-1-78242-454-3.00007-x

[4] R. Anokye, E. S.Bakar, J. Ratnansingam \& K. Awang,. Bamboo Properties and Suitability as a Replacement for Wood Pertanika Journal of Scholarly Research Reviews. PJSRR 2(1): 63-79, 2016. eISSN: 2462-2028C Universiti Putra Malaysia Press. http://www.pjsrr.upm.edu.my/

[5] MS 544 Part 2. (2001). Permissible Stress Design Of Solid Timber. (SIRIM, Ed.), Code of practice for structural use of timber: PART 2: Permissible stress design of solid timber (First). Standard and Industrial Research Institute of Malaysian (SIRIM), Shah Alam, Malaysia.

[6] Malaysian Timber Council. (n.d.). Mengkulang. Retrieved 17 September 2021, from http://mtc.com.my/wizards/mtc_t $\mathrm{ud} /$ items/report(71).php

[7] MS 758. (2001). Glued Laminated Timber - Performance Requirements and Minimum Production Requirements. Standard and Industrial Research Institute of Malaysian
(SIRIM), Shah Alam, Malaysia.

[8] MS 544 Part 3. (2001). Glued Laminated Timber. Standard and Industrial Research Institute of Malaysian (SIRIM), Shah Alam, Malaysia.

[9] MS 544 Part 5. (2017). Timber Joints. (SIRIM, Ed.). Standard and Industrial Research Institute of Malaysian (SIRIM), Shah Alam, Malaysia.

[10] K.W. Johansen. Theory of timber connections. IABSE Publications, 9, 249-262, 1949. https://doi.org/10.5169/seal s-9703

[11] NDS. National Design Specification for Wood Construction American Forest and Paper Association (AFPA) Washington D.C. (2005).

[12] Eurocode 5. Design of Timber Structures. (BS EN 1995 -1-1-2004 +A1: 2008).

[13] H. Stamatopoulos \& K. A. Malo. On strength and stiffness of screwed-in threaded rods embedded in softwood. Construction and Building Materials, 261, 119999. (2020). https://doi.org/10.1016/j.conbuildmat.2020.119999

[14] ASTM. ASTM D1761 - Standard Test Methods for Mechanical Fasteners in Wood. ASTM. ASTM. https://doi.org/10.1520/D1761-12. (2012). Copyright

[15] R. Hassan. N. J. Abd Malek, M. N. Shakimon, S. M. Sapuan. Parallel Glueline of Withdrawal Capacity for Mengkulang Glulam. July 2021. Environment-Behaviour Proceedings Journal 6(SI4):223-231. DOI:10.21834/ebpj.v6iSI4.3030

[16] N. J. Abd Malek, L. S. Hui, R. Hassan. Performance of Withdrawal Capacity for Mengkulang Glulam Perpendicular to the Glue Line for $14 \mathrm{~mm}$ and $20 \mathrm{~mm}$ Bolt Diameter. International Journal of Innovative Technology and Exploring Engineering (IJTTEE) ISSN: 2278-3075, Volume-9 Issue-3, January 2020. DOI: 10.35940/ijitee.C9221.019320

[17] P. E. H. Ab. Rahman, M. S. Sabri, N. S. Zakaria, F. N. M., Anuar, A. Zainal, R. Hassan. Effects of Embedment Depth on Withdrawal Resistance of Timber Dowelled Connection Made from Merbau Species. International Transaction Journal of Engineering, Management, \& Applied Sciences \& Technologies, 12(9), 12A9C, 1-8. http://TUENGR.COM/V12/12A9C.pdf DOI: 10.14456/ITJEMAST.2021.171

[18] Y. Ahmad. Bending Behavior of Timber Beams Strengthened Using Fiber Reinforced Polymer Bars and Plates. PhD thesis. University Teknologi Malaysia. 2010.

[19] D. Brandon. Fire and structural performance of non-metallic timber connections. Master Science Thesis. University of Bath. 2018.

[20] S. R. S. Monteiro, C. Martins, A. M. P. G. Dias, \& H. Cruz. Mechanical performance of glulam products made with Portuguese poplar. European Journal of Wood and Wood Products, 78(5), 1007-1015. 2020. https://doi.org/10.1007/s 00107-020-01569-y.

[21]P. Racher, K. Laplanche, D. Dhima, \& A. Bouchaïr, Thermo-mechanical analysis of the fire performance of dowelled timber connection. Engineering Structures, 32(4), 1148-1157, 2010. https://doi.org/10.1016/j.engstruct.2009.1 
2.041

[22] M. N. Shakimon, N. J. Abd Malek, R. Hassan, and Z. Ahmad. The Finite Element Modelling of Glulam. Jurnal Teknologi, 78(5), 75-78. 2016

[23] S, Abu Bakar, A.L. Saleh and Z. Mohamed. Factors affecting ultimate strength of solid and glulam timber beams. Jurnal Kejuruteraan Awam, 16(1), 38-47. 2004.

[24] B. H. Xu, M. Taazount, A. Bouchaïr, \& P. Racher, Numerical 3D finite element modelling and experimental tests for dowel-type timber joints. Construction and Building Materials, 23(9), 3043-3052. 2009. https://doi.org/10.1016/j .conbuildmat.2009.04.00

[25] L Guo, Xiang, J.P. Latham, \& B. Izzuddin. A numerical investigation of mesh sensitivity for a new three-dimensional fracture model within the combined finite-discrete element method. Engineering Fracture Mechanics, 151,70 91.2016 .https://doi.org/10.1016/j.engfracmech.2015.11.006

[26] O. A. Vilguts, D. Serdjuks, \& L. Pakrastins. Design methods of elements from cross-laminated timber subjected to flexure. Procedia Engineering, 117(1), 10-19, 2015. https://doi.org/10.1016/j.proeng.2015.08.117
[27] N. Tanlak, F. O. Sonmez \& E. Talay. Detailed and simplified models of bolted joints under impact loading. Journal of Strain Analysis for Engineering Design, 46(3), 213225.2011. https://doi.org/10.1177/0309324710396997

[28] M. Ardalany, M. Fragiacomo, B. Deam, \& K. Crews. Analytical cracking load estimation of Laminated Veneer Lumber (LVL) beams with holes. European Journal of Wood and Wood Products, 71(1), 37-48, 2013. https://doi.org/10.1007/s00107-012-0646-3

[29] A. Korolija. FE-modeling of bolted joints in structures Master Thesis in Solid Mechanics Alexandra Korolija Title of series. 2012. Linköping University.

[30] Anonymous. https://kis.tu.kielce.pl/mo/COLORADO_FEM /colorado/IFEM. Retrieved 2 April 2021.

[31] N. T. Mascia \& F. A. R. Lahr. Remarks on orthotropic elastic models applied to wood. Materials Research, 9(3), 301-310. 2006. https://doi.org/10.1590/S1516-14392006000300010

[32] D. W. Green, E. Jerrold, D. E. K. Winandy. Mechanical properties of wood. In Wood handbook: Wood as an engineering material (pp. 4-1-4-45). 1999. Madison, WI: US Forest Department of Agriculture. https://doi.org/10.2472/jsms.21.899 